\title{
OS LAGOS DO IBIRAPUERA COMO ESTRUTURAÇÃO HÍDRICA DE UM PARQUE
}

THE IBIRAPUERA LAKES AS HYDRIC STRUCTURE OF A PARK

\author{
Riciane Maria Reis Pombo \\ Arquiteta Urbanista graduada pela Universidade Presbiteriana Mackenzie, São Paulo \\ Membro do Conselho Gestor do Parque Ibirapuera, gestão 2015-2017 \\ E-mail: pomboarquitetura@gmail.com
}

\begin{abstract}
RESUMO
O artigo a seguir visa uma análise diferenciada do parque urbano mais frequentado da cidade de São Paulo, tendo a água como referência. Analisando diversos textos, de diferentes autores, foi observado que há muitos relatos sobre a história do parque, desde sua idealização, passando por sua implantação, até a situação atual. Também foram encontradas análises críticas abordando várias questões, como política, arquitetura, paisagismo, utilização dos espaços pelos usuários, etc. Mas pouco encontramos sobre os lagos e sobre sua relação com o projeto elaborado para o parque, além de arquivos históricos com registros dos diversos projetos elaborados para a despoluição de suas águas. Este texto tem a intenção de esclarecer como a implantação e a utilização da área destinada ao Ibirapuera ocorreu e ainda ocorre segundo as necessidades da sociedade, e como é a relação desta sociedade com a paisagem local. Como foi a transformação de uma grande área ecológica em um parque urbano, construído para simbolizar o progresso? Qual o papel dos lagos na estrutura do parque? Quais os processos envolvidos na transformação da área? Como os lagos são vistos pelos usuários e como é a relação das pessoas com os lagos? Estas e outras questões serão respondidas a partir de consulta a materiais bibliográficos, arquivos oficiais e também através de análises e visitas ao local, bem como por entrevistas a pesquisadores e funcionários do parque.
\end{abstract}

Palavras-chave: Arquitetura; Lago; Parque Ibirapuera; Estrutura hídrica; Paisagismo. 


\begin{abstract}
This article aims to achieve a different analysis of the most visited urban park in the city of São Paulo, having its water as reference. By analyzing texts from different authors, it was noted that there are many reports of the history of that park, from its conception, through its implementation until the current situation. It was also found critical analyzes approaching several issues such as politics, architecture, landscaping, use of spaces by users etc. However, a little was found about the lakes and its relationship with the conception design of the park, but just historical files with records of various projects to clean up pollution its waters. This work intends to clarify how the implementation and use of the Ibirapuera area has occurred - and still occurs - according to the needs of the society. It also intends to explain how the relationship of the society with the local landscape is. How has occurred the transformation of a large ecological area in an urban park, built to symbolize progress? Which is the role of those lakes in the structure of the park? Which are the processes involved in the transformation of that area? How are the lakes considered by its users and how the relationship between people and the lakes is? These and other questions will be answered by the results of bibliographic search, official files and also through analysis and visits to that site, as well as interviews with researchers and park staff.
\end{abstract}

Keywords: Architecture; Lake; Ibirapuera Park; Water Structure; Landscaping.

\title{
INTRODUÇÃO
}

Na cidade de São Paulo temos diversos problemas relacionados à questão da drenagem urbana e poluição das águas, solos e ar. Grande parte desses problemas se justificam pela má qualidade da estrutura do próprio sistema de drenagem, que não atende ao fluxo e vazão das águas pluviais e esgoto, bem como ao sistema viário e ao histórico de ocupação urbana.

"O ciclo hidrológico sofre fortes alterações nas áreas urbanas devido, principalmente, à alteração da superfície e à canalização do escoamento, aumento de poluição devido à contaminação do ar, das superfícies urbanas e do material sólido disposto pela população." (Tucci) 
Todo o sistema de drenagem da cidade foi pensado de forma a afastar os rios e córregos da área urbanizada, pois os mesmos com o tempo se transformaram em meio de transporte de esgoto. Todos os planos urbanísticos propostos para a metrópole beneficiaram a circulação rodoviária, e progressivamente os rios e córregos foram sendo canalizados, retificados, e assoreados dando lugar a ruas e avenidas, de modo a ampliar circulação viária e esconder os rios mal cheirosos. Assim, aos poucos a população foi perdendo o contato com os cursos d'água e hoje, os poucos remanescentes visíveis se encontram poluídos. $\mathrm{A}$ sociedade não se identifica com seus rios e córregos, pois houve um processo gradativo e contínuo de degradação e esquecimento de todo o ecossistema natural da cidade.

Na região da bacia do Córrego do Sapateiro não foi diferente. A área toda sofreu com as intervenções urbanísticas desde o início do crescimento da industrialização da cidade. A abordagem deste assunto visa resgatar a história de uma das regiões mais valorizadas de São Paulo e mostrar como a implantação do Parque do Ibirapuera foi executada a partir da necessidade de se resolver a questão da drenagem pluvial da região. Além de contar esta história a partir de um uma análise ambiental, a intenção aqui é também contar um pouco como foi a transformação dos cursos d'água da cidade ao longo dos tempos e tentar entender a formação da cidade a partir deste viés.

\section{RESUMO HISTÓRICO DA IMPLANTAÇÃO DO PARQUE}

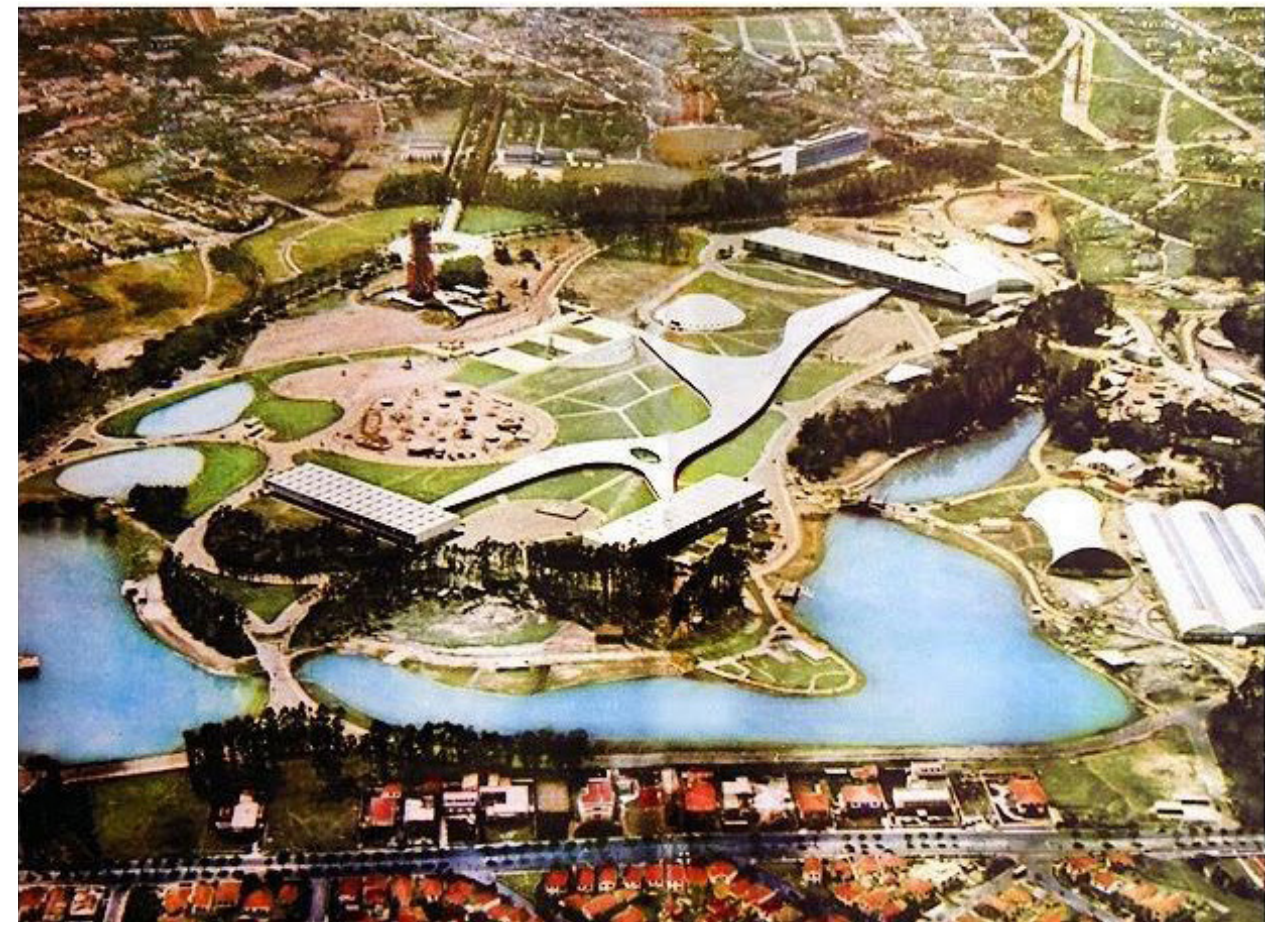

Figura 1 - Parque Ibirapuera.

Fonte: Arquivo Histórico Municipal. 
Inicialmente idealizado pelo prefeito Pires do Rio como uma área de lazer e preservação da área verde restante na cidade, o Parque do Ibirapuera (figura 1) se concretizou como um marco da vitória do modernismo e da metropolização de São Paulo. Um parque construído sob os moldes de cidades americanas e europeias, tidas como referência de urbanização e modernização na época de sua implantação, representa o crescimento e a industrialização da maior e mais imponente cidade do país.

A cidade vivia um período de crescimento industrial muito acelerado, e aspirava estar entre as cidades mais importantes do mundo. Portanto, deveria possuir todas as características de beleza, higiene e lazer dignas de uma cidade de grande porte.

Muitos interessados na região, que valorizava-se cada vez mais rápido, alegavam propriedade de glebas e isso também dificultou e atrasou a implantação do parque. Estado e município se dividiam também no interesse por essa área, reivindicando a implantação de equipamentos estruturais como aeroporto, avenidas e sedes de órgãos públicos.

A área que antes chegou a abrigar chácaras e pastagens tornou-se alvo de grande especulação imobiliária. Mas a prefeitura, desde o momento em que recebeu as terras devolutas, já intentava manter ali um grande parque para preservação de área verde, a fim de melhorar as condições de salubridade, higiene e lazer dos moradores da cidade que crescia em ritmo acelerado. O que impactou e transformou o rumo do parque foram as dificuldades e intervenções surgidas com o decorrer do tempo e, claro, da contínua mudança de poder que houve durante o desenrolar de tantos processos.

A época era de evolução no urbanismo, as avenidas e as grandes obras de infraestrutura eram símbolo do progresso da maior cidade do país. A industrialização representava a mãe do progresso, juntamente com o poder político da época, que foi o pai provedor e a autoridade máxima nas decisões. A eufórica sociedade, com a ideia do marco que o parque viria a ser para a cidade, não conseguiu impedir que tantas construções ocupassem o lugar dos córregos e das áreas verdes preexistentes. O pensamento higienista da sociedade e da política da época fez com que os córregos e rios que por ali passam, assim como todos da cidade, fossem escondidos, remanejados, para dar passagem a avenidas e viadutos.

Houve até mesmo bastante movimento em prol de um parque mais verde, por parte de alguns setores organizados da sociedade e da mídia jornalística, representada 
principalmente pelo jornal O Estado de São Paulo. Até mesmo dentro do poder público havia discordâncias.

Para a implantação dos equipamentos que contemplariam o programa do parque, muito teve que ser modificado na paisagem natural. Não teria sido possível implantar edificações num terreno tomado pelas águas e pela vegetação nativa. Foram plantados eucaliptos australianos para secar a terra e "remediar" o problema da umidade excessiva da região. No viveiro ali presente, eram reproduzidas diversas espécies arbóreas, arbustivas e herbáceas que foram introduzidas no terreno. Os córregos foram canalizados e escondidos embaixo das ruas e avenidas, pois só serviam como transporte de esgoto. Com o tempo, os lagos deixaram de ser utilizados para o lazer, pois passaram a receber grande quantidade de detritos e suas águas ficaram impróprias desde então, e assim continuam. Novas tecnologias e materiais foram trazidos, o concreto representava o máximo da modernidade na construção civil. $O$ desenho de Niemeyer para as edificações trazia o que havia de mais audacioso na arquitetura. A inovação era importante para uma cidade pioneira. Grande parte da área do parque foi destinada a essas construções e às avenidas. Prevaleceu o concreto sobre a natureza.

Foi acirrada a disputa para a escolha dos representantes e participantes dessa grande obra, desde decisões políticas sobre o programa do parque, até a escolha das empresas e dos profissionais responsáveis pelos projetos e pela execução de cada serviço. Todos queriam seu nome nesse marcante projeto.

A população não conseguiu impactar nas decisões como gostaria, mas muito barulho foi feito. A grande maioria pedia por um parque mais verde. Parcerias políticas e amizades influenciaram a determinação da Comissão para o IV Centenário, criada para direcionar todas as decisões. A mesma tinha a presidência de um grande industrial, Ciccilio Matarazzo. Não foi à toa que inicialmente se concebeu o palácio das indústrias, para abrigar uma grande feira de tecnologia. Nem tampouco foi à toa que outras edificações foram concebidas para abrigarem órgãos públicos.

O programa de atividades para as festividades também se voltava à industria e ao comércio, bem como às exposições de artes e cultura, tudo de modo a celebrar uma grande metrópole. Ademais, boa parte da área, que pertencia ao poder público, foi também destinada à urbanização e à criação de bairros e comercializada ao setor privado. 


\section{A QUESTÃO DOS LAGOS}

A área do atual parque era destino da drenagem dos bairros de Vila Mariana, Paraíso e Vila Clementino. Portanto, uma região alagadiça, de brejo e charco, pois se situa em bacia de fundo de vale. Além disso, acomoda as várzeas de inundação dos córregos do Sapateiro, Caaguaçu e Uberaba.

O Parque do Ibirapuera ilustrou uma chance oportuna de preservar do parcelamento e ocupação um sítio de fragilidade ambiental, em bacia de fundo de vales e em vertente condutora de drenagens. Se a reserva da área foi importante, a proposta de Teixeira Mendes não seria menos. ${ }^{1}$

O Parque do Ibirapuera, palco dos festejos, tinha a responsabilidade de expressar a vanguarda e a modernidade que a cidade almejava possuir. Paradoxalmente, na indireta proporção em que o parque passou a ser reconhecido como referencial na metrópole paulistana, sua autoria (Otávio Augusto Teixeira Mendes) no paisagismo e coparticipação no projeto foi sendo eclipsada. ${ }^{2}$

O projeto de Teixeira Mendes, desenvolvido em 1953, priorizava a composição do parque como um todo, e não focava no entorno imediato das edificações, como foi o caso de outros projetos. O regionalismo também era uma característica marcante de seus projetos, valorizando não somente a cultura, como também a paisagem nacional. Por ter vivido uma experiência no exterior, suas influências incluíam o paisagista Frederick Law Olmsted e, assim, a importância dos cursos d'água no desenvolvimento do projeto paisagístico foi fundamental. Aliás, a água era uma questão não somente importante, mas limitadora para a implantação do parque naquela área. Uma das exigências da companhia de saneamento da época, RAE, era a de que se pensasse numa forma de reter e canalizar as águas dos córregos e das chuvas abundantes, prevendo assim, a possibilidade de alagamentos futuros.

Então o projeto de Teixeira Mendes surge da criação de vias de circulação que favorecessem a visão da paisagem em diversas composições, serpenteando os edifícios e os lagos. A paisagem como arte para ser vivida era o aspecto norteador de seus projetos, e ali era isso o que importava. A água foi um dos elementos determinantes para a composição estética do projeto, arrematando os lagos aos edifícios e aos cór-

\footnotetext{
1 MARIANO, Cassia. Preservação e Paisagismo em São Paulo. p. 104.

2 Ibidem. p. 111.
} 
regos existentes, de maneira a criar uma drenagem natural dos mesmos e direcionar os excedentes pluviais.

Os lagos são cheios de curvas e sinuosidades, criando assim diversos horizontes e paisagens, ao mesmo tempo em que dão destaque às construções, como foi solicitado. Além do clima de sossego e da bela reflexibilidade de suas águas, os lagos também cumpriram com êxito, até então, a função de armazenar as águas dos córregos e das chuvas.

A construção do lago envolveu sua formação, desassoreamento dos materiais na cabeceira do córrego Itororó e a faixa de regularização do modelado na distância mínima de trinta metros a partir do perímetro. As especificações definiam que o terreno ao final do movimento deveria apresentar superfície uniforme e limpa de materiais não terrosos.

As escavações mantiveram a profundidade do lago mínima definida em 1,20 metros, estivando o terreno pouco consistente com peças de eucaliptos. 0 memorial especificava a cota mínima de 745,00 para a execução dos aterros regularizados, estabelecendo transição entre a saia do talude e o terreno natural com compactações calcadas com cilindros de pé de carneiro de 12 toneladas em camadas de meio metro. Finalizou-se o recobrimento da camada superficial com o solo da própria área, como providência para otimizar o crescimento da vegetação. A inclinação dos taludes, na exata razão de 1:3, confere estabilidade e transição branda para as margens no limite entre terra e água. A espacialidade obtida por essa diretriz caracteriza o espraiamento e é responsável pela percepção de placidez atribuída aos lagos do parque.

Os trabalhos deveriam computar o espalhamento da terra no local do botafora, de forma que a passagem das máquinas pudesse contribuir com alguma compactação do terreno. Os dois córregos foram ligados e nesse trabalho feito à escavadeira era fundamental não prejudicar a tubulação de esgotos existente numa cota pouco inferior a do nível da escavação. ${ }^{3}$

\section{INTERVENÇÕES NOS LAGOS DO IBIRAPUERA}

O que antes eram lagos limpos e usados como forma de lazer e práticas de esportes, hoje só podem ser contemplados como parte da paisagem. Os lagos do parque Ibirapuera há muito passam por problemas de poluição em suas águas, devido a diversos

\footnotetext{
${ }^{3}$ Ibidem. p. 117-8.
} 
fatores: esgotos clandestinos, lixo trazido pelas águas pluviais, lodo... A profundidade que antes era de 2,50 metros, hoje não passa de $0,50 \mathrm{~cm}$ em vários pontos.

Apesar de haver registros antigos de diversos projetos e iniciativas para a melhoria das águas, o problema é reincidente, pois os córregos que alimentam os lagos são fontes de constante poluição. Muito já foi gasto com ações de desassoreamento, diques de contenção e até uma estação de tratamento por flotação foi implantada no córrego do Sapateiro. Mas como a mesma tem dimensão reduzida, facilmente as águas pluviais extravasam sua capacidade e todo o trabalho acaba por ser perdido.

Outra intervenção com a intenção de melhorar a aeração da água foi a implantação das fontes do lago 1 que, além da beleza proporcionada pelos shows das "águas dançantes", também movimentam a água aumentando o nível de oxigênio.

Segundo a administração do parque, atualmente é feita a limpeza manual diária nos lagos por funcionários a bordo de um barco com ajuda de um rastelo. Eles retiram cerca de 100 quilos de lixo por dia, sendo que em dias de chuva esta quantidade chega a 300 quilos. Ou seja, é uma manutenção constante, exaustiva e pouco eficiente.

\section{ALGUMAS INTERVENÇÕES NOS LAGOS:}

\section{A cabine secreta}

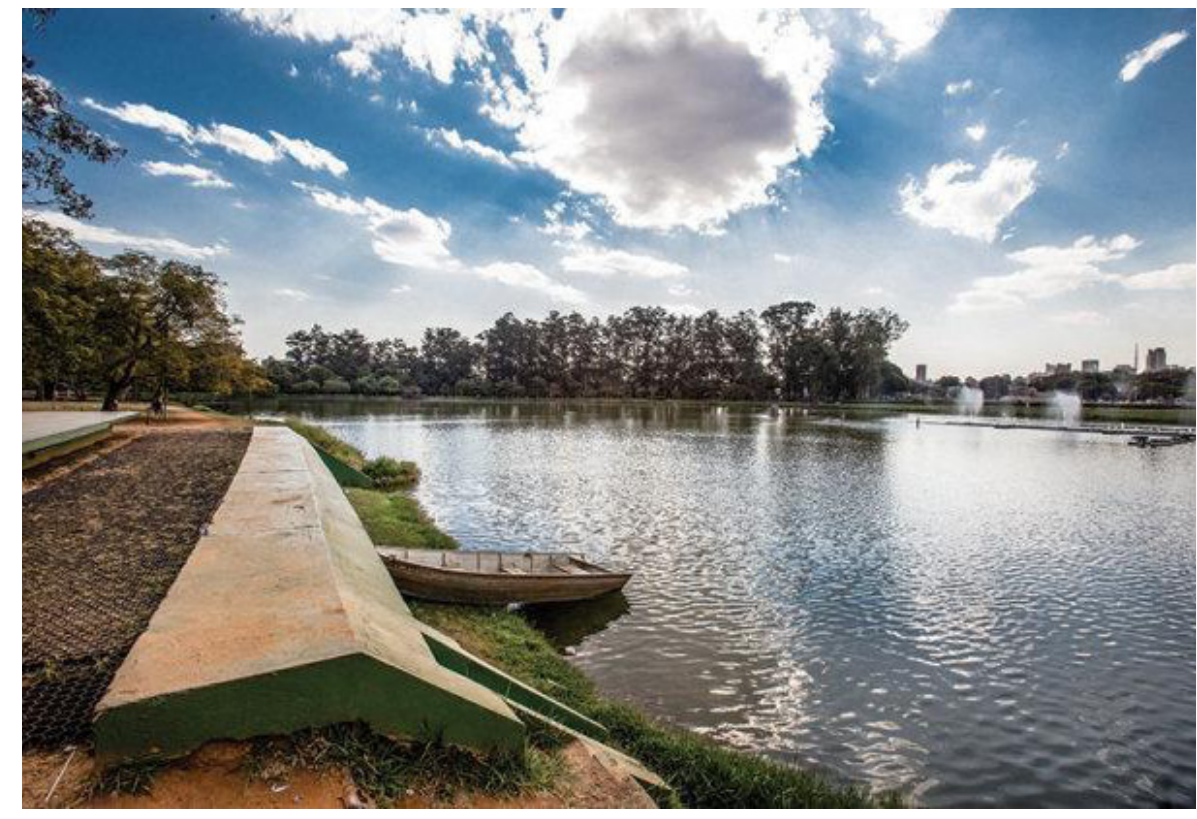

Figura 2 - A cabine secreta. Ao lado do barco, há uma cabine subterrânea de onde se controla as fontes do lago.

Foto: Wanezza Soares. 
Os jatos dançantes da fonte do lago são controlados em uma cabine subterrânea de 70 metros quadrados (o espaço escondido está ao lado da canoa na imagem acima). Equipado com computador, projetores e motores, o quartel-general camuflado é o cérebro do balé que envolve os 420 bicos de água.

\section{Desfile de sereias}

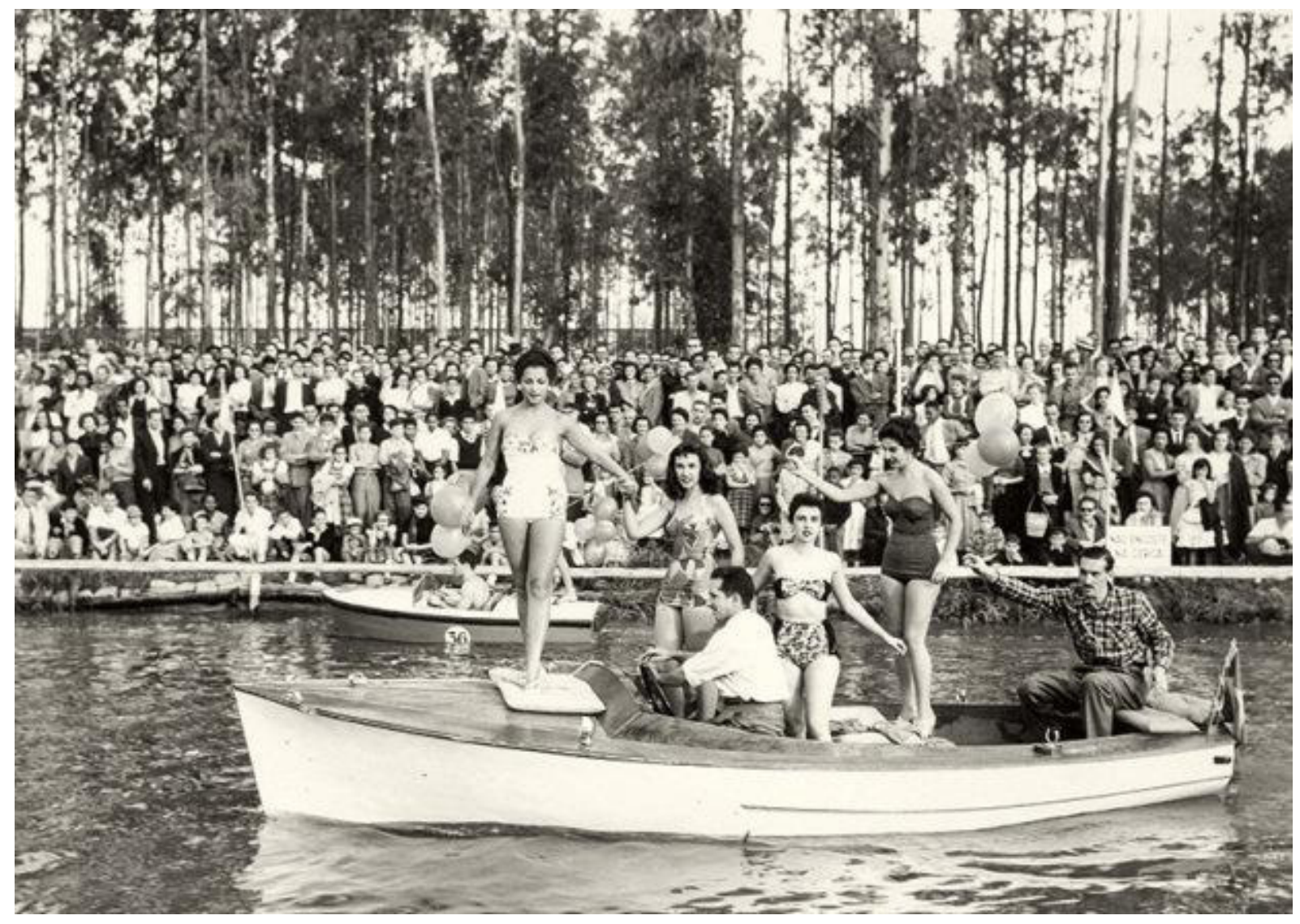

Figura 3 - Desfile de sereias. Para a festa de inauguração, uma das atrações foi o desfile a bordo de barcos das chamadas "sereias" em trajes de banho. Foto: Estadão Conteúdo.

\section{Balé no lago}

Entre as várias atrações do dia da inauguração, um grupo de 55 nadadores saudou o público com uma apresentação artística nas águas do lago. Logo depois do balé, houve o desfile das chamadas "sereias" em maiôs e biquínis. 


\section{Salão do automóvel}

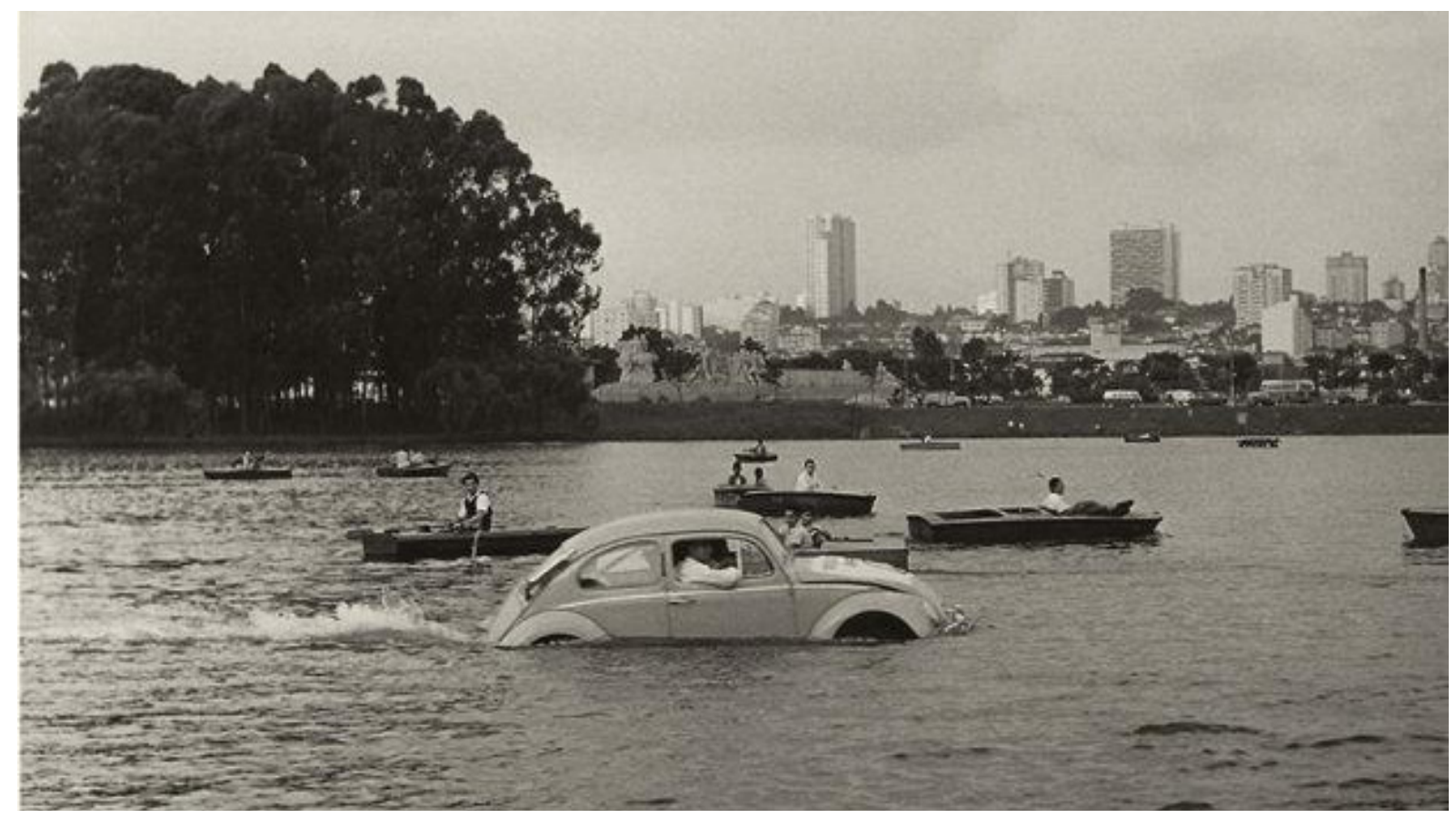

Figura 4 - Salão do Automóvel. Um fusca adaptado singrou pelas águas do lago durante a primeira edição do Salão do Automóvel, em 1960. (Foto: Divulgação/Volkswagen).

A primeira edição do evento aconteceu em novembro de 1960. Um Fusca adaptado para se tornar "anfíbio", com o objetivo de impressionar o público, disputou espaço com os barquinhos no lago4.

\section{CONCLUSÃO}

Afinal, podemos considerar os lagos do Ibirapuera como uma estruturação hídrica do parque?

Como um dos maiores obstáculos à implantação do parque foi a questão do terreno, que originalmente era uma várzea, fica evidente que a criação dos lagos para captar e direcionar as águas que irrigam a área foi uma solução eficiente e ao mesmo tempo

\footnotetext{
${ }^{4}$ Revista Veja SP online. Disponível em: <http://vejasp.abril.com.br/materia/parque-ibirapuerahistorias-inusitadas-60-anos-lago/>.
} 
criou uma paisagem que transformou o parque em um local especial e único na cidade, que atrai os usuários e turistas para suas margens. O resultado que esta solução trouxe foi a transformação de uma grande área de várzea em um grande e importante parque urbano, que funciona como um oásis na paisagem da cidade.

A questão da drenagem urbana, muitas vezes pensada como forma de esconder e afastar o esgoto das regiões mais valorizadas da cidade, gerou diversos problemas como alagamentos e dificuldades de manutenção e monitoramento dos cursos d'água. Também criou um afastamento e esquecimento desses rios e córregos da vivência e cultura da sociedade, pois hoje grande maioria se encontra canalizado e subterrâneo, ou seja, não fazem parte da paisagem urbana e nem da vida da população. Suas margens foram invadidas por asfalto e concreto, e a vegetação e fauna foram totalmente extintas.

Já no caso do parque Ibirapuera, notamos que a água centralizou e direcionou não somente o desenho do parque, mas também o uso e a apropriação do espaço público pela sociedade, garantindo a preservação de uma área verde importante para a cidade.

Hoje o parque é tido como um dos dez melhores parques urbanos do mundo, segundo pesquisas públicas internacionais. O melhor da América do Sul. Continua sendo um marco e é um orgulho para os paulistanos e para todo o país. Com certeza a experiência promovida pela presença dos lagos é fator determinante para essa aprovação pública, mas também é certo que a maioria dos usuários gostaria de poder usufruir mais amplamente desse bem precioso.

\footnotetext{
Em pleno século XXI, está evidente a importância do planejamento do meio físico urbano; no entanto, a preocupação de quem planeja ainda está centrada nas características sócio-econômicas, relegando a dependência dos elementos naturais. No decorrer do processo de expansão dos ambientes construídos pela sociedade, não se tem dado a devida atenção à qualidade, sendo as questões ambientais e sociais relegadas ao esquecimento. ${ }^{5}$
}

${ }^{5}$ LOBODA, Carlos Roberto; ANGELIS, Bruno Luiz Domingos De. Áreas Verdes Públicas Urbanas. 


\section{REFERÊNCIAS BIBLIOGRÁFICAS}

ANDRADE, Manuella Marianna Carvalho Rodrigues de. O Processo Histórico de Formação do Parque do Ibirapuera. São Paulo: Departamento do Patrimônio Histórico Divisão do Arquivo Histórico Municipal "Washington Luís".

BARONE, Ana Claudia Castilho. Ibirapuera: parque metropolitano (1926-1954). São Paulo: FAUUSP, 2007. (Tese de doutorado).

BARTALINI, Vladmir. Parques públicos municipais de São Paulo: a ação da municipalidade no provimento de áreas verdes de recreação. São Paulo: FAUUSP, 1999. (Tese de doutorado).

LOBODA, Carlos Roberto; ANGELIS, Bruno Luiz Domingos de. Áreas Verdes Públicas Urbanas: Conceitos, Usos e Funções.

LOFEGO, Silvio Luiz. IV Centenário da Cidade de São Paulo: uma cidade entre o passado e o futuro. São Paulo: Annablume, 2004.

LOVELOCK, James. As Eras de Gaia, uma biografia do nosso planeta vivo. Portugal: Publicações Europa América Ltda., 1989.

MARIANO, Cassia. Preservação e Paisagismo em São Paulo: Otávio Augusto Teixeira Mendes. São Paulo: Annablume, Fapesp, Fundação Maria Luisa e Oscar Americano, 2005.

MOSES, Robert. Programa de melhoramentos públicos para a cidade de São Paulo. Revista do Instituto de Engenharia, São Paulo, n. 103, v. 5, mar. 1951, p. 321-7.

ODUM, Eugene P. Fundamentos de Ecologia. Lisboa: Fundação Calouste Gulbekian, 1976.

OLIVEIRA, Fabiano Lemes de. O Parque do Ibirapuera: projetos, modernidades e modernismos. DOCOMOMO_5, São Paulo, 2014.

OLIVEIRA, Fabiano Lemes. Projetos para o Parque do Ibirapuera: de Manequinho Lopes a Niemeyer (1926-1954). São Paulo, 2003. (Dissertação de Mestrado).

SEGAWA, Hugo. Ao amor do público: jardins no Brasil. São Paulo: Studio Nobel; FAPESP, 1996. (Cidade aberta). 